\title{
AOR
}

Selected Papers of \#AoIR2020:

The $21^{\text {st }}$ Annual Conference of the

Association of Internet Researchers

Virtual Event / 27-31 October 2020

\section{THE INTERNET IS TRASH: MAKING SENSE OF TOXIC NETWORKS}

\author{
Amber Buck \\ University of Alabama, USA \\ Cindy Tekobbe \\ University of Alabama, USA \\ Dustin Edwards \\ University of Central Florida, USA
}

Dumpster Fire. Garbage Site. Trash Heap. The flotsam and detritus of the unfettered growth and transformation of digital life. Particularly since Brexit and the American presidential election of 2016, which brought this digital refuse to the forefront of public discourse, Internet scholars have been coming to terms with the societal consequences of some of the issues they have been warning about for years, including online harassment, surveillance, and state-sponsored disinformation campaigns. Whitney Philips (2020) recently described the internet as a "toxic hellscape" in Wired magazine, arguing for collective problem solving and our own agency in working together to fix the internet's problems. Lisa Nakamura's 2020 TED talk called the internet a "trash fire," before suggesting solutions like content moderation. Artist Jenny Odell (2019), on the other hand, has advocated for disconnection as a solution to toxic spaces and the attention economy itself.

This panel brings together scholars studying distinct aspects of internet culture in order to make sense of the negative byproducts of online spaces. Each presenter takes on a different topic: political internet memes, fan subcultures, and physical digital waste to consider the consequences of internet life. Using distinct methodologies: case study interviews, textual studies and histories, and autoethnography, this panel considers what internet scholars can learn from the unsavory parts of the internet.

Buck describes and discusses their study of political meme sharing communities in the context of the 2020 North American election cycle to explore how these memes function in closed communities. Buck finds that these "trash" memes can act as identity markers

Suggested Citation (APA): Buck, A.; Tekobbe, C. \& Edwards, D. (2020, October). The internet is trash: Making sense of toxic networks. Panel presented at AolR 2020: The 21 $1^{\text {th }}$ Annual Conference of the Association of Internet Researchers. Virtual Event: AolR. Retrieved from http://spir.aoir.org. 
that serve to bolster political identity, construct community, and foster political life online. Tekobbe introduces their study of the comments and discussion threads of one slash fandom Facebook group - a context that intersects both the "trashy" practice of writing and reading fanfiction and the hostile online detritus of social platform user interactions online - exploring ways one fandom group works together to construct productive and collegial discussion and creative threads. Tekobbe finds that with specific group scaffolding in place, an online space can become collaborative and self-moderating, a livable space model of positive production rather than so much garbage interactions. Speaker 3, employing feminist and indigenous methodologies, tells the stories of one mining town as a microcosm for larger considerations of an embodied and embedded view of internet life and death. Using a "thick"ened concept of battery life, Edwards considers the long term ecological consequences of digital technology production waste.

Working with notions of internet waste, these presentations serve to build out a broad set of perspectives about the potential value in the trash internet, what we can learn from it, and how we can think more deeply about that which has little value or consideration in the internet life of clicks, posts, shares, likes, and follows. Through these presentations, the speakers ask the audience to consider their own views of internet garbage and to think about remedies to the toxic ecologies that impact life both virtual and literal.

\section{References}

Nakamura, L. (2020). TED talk: The internet is a trash fire. Here's how to fix it. YouTube. Retrieved from https://www.ted.com/talks/lisa nakamura the internet is a trash fire here $\mathrm{s} \mathrm{h}$ ow to fix it

Odell, J. (2019). How to Do Nothing: Resisting the Attention Economy. Melville House.

Phillips, W. (2020, Feb 3). The Internet Is a Toxic Hellscape-But We Can Fix It. Wired. Retrieved from https://www.wired.com/story/the-internet-is-a-toxic-hellscape-butwe-can-fix-it/ 


\title{
ACR
}

Selected Papers of \#AolR2020:

The $21^{\text {st }}$ Annual Conference of the

Association of Internet Researchers

Virtual Event / 27-31 October 2020

\section{THE INTERNET'S DANK MEME STASH: EXAMINING POLITICAL MEMES IN INTERPRETIVE COMMUNITIES}

\author{
Amber Buck \\ University of Alabama
}

\section{Background}

Internet memes, especially image-based macros, have become not only an established means of communication in networked environments, but also genres through which individuals make cultural meaning. Scholars such as Ryan Milner (2016) and Limor Shifman (2014) have examined the centrality of memes for internet discourse. Milner has described memes as "a lingua fracta for digitally mediated participation." For Shifman, while memes circulate through different internet communities, they also "shape and reflect general social mindsets" (p. 4). The ways in which memes are both collectively constructed and flexible as a delivery system for different kinds of information make them a productive avenue for academic study.

As Shifman (2014) argued, memes are especially popular for communication about current news events and politics. Shifman identified three primary functions for political memes: 1) generated by candidate campaigns themselves for persuasion; 2) created by individuals for grassroots action; and 3) generally, serving as modes of "expression and public discussion" (p. 123). While work from Shifman and Milner point to the creative nature of memes to remix content and comment on current events, this work and other scholarship research and conducted before 2016 (Jenkins et al., 2013) is often positive, or at least ambivalent, on the ability of memes to speak truth to power and to comment on news and political events, bringing average citizens and activists into conversation on the ways that speak back to political and media establishments.

More recent work on memes has considered the ways that political memes work for exclusion rather than inclusion. Ross and Rivers (2017) have found delegitimization to be a common strategy in memes constructed around the 2016 U.S. Presidential election. The creation and circulation of internet memes served to reduce the legitimacy

Suggested Citation (APA): Buck, A. (2020, October). The internet's dank meme stash: Examining political memes in interpretive communities. Paper presented at AoIR 2020: The $21^{\text {th }}$ Annual Conference of the Association of Internet Researchers. Virtual Event: AolR. Retrieved from http://spir.aoir.org. 
of Donald Trump and Hillary Clinton as candidates, rather than to energize different communities to support them. Erika Sparby (2017, Forthcoming) has also noted the ways that memes, and political memes in particular, reify and amplify positions rather than persuade audiences.

Indeed, political memes in particular have had a decidedly mixed history when it comes to persuasion. Because memes work as a type of cultural shorthand, they often truncate arguments and ideas and rely on rhetorical commonplaces. Ryan Milner (2016) described internet memes as polyvocal systems through which multiple meanings and identities are negotiated. Memes are created collectively; they become codified over time into recognizable genres and gain meaning through repetition and reinterpretation. Shifman (2014) argued that some political memes can be ambiguous: liberal audiences might read them one way and conservatives another, but in many instances, memes also best make meaning in closed interpretive communities. In China, Shifman (2014) noted, meme creators use creative symbolism to get images and messages past internet censors - for example, using the image of river crab to represent censorship.

\section{Internet Memes in Closed Communities}

Recent research on fake news and disinformation in networked publics can also help scholars understand the ways that political internet memes function and circulate on social media platforms. In her examination of fake news on social media, Alice Marwick (2018) found that individuals share fake news as a way to signal identity. Whether or not the information is true is secondary, and the circulation of such content instead signals the sharer as a member of a particular group. Much of this information is shared not only through news links, but also through image-based memes. Francesca Tripodi (2018) has also described the ways in which conservative political groups use language in specific ways that have distinct meanings within their communities and functions to reify in-group beliefs and information sharing.

More research, then, is needed on how and why individuals share political memes and how they function within and between different online communities. This study considers the motivations behind internet users' sharing and circulation of political memes within their personal networks on social media. While image macros are easy to share beyond their original context (Gries, 2015), they also rely on shared knowledge and a common language to make meaning. In many ways, memes create humor within particular in-groups, though the technologies through which they are shared encourage circulation beyond those groups.

\section{Methodology}

This study reports on qualitative interviews with social media users who frequently share political memes. The author is conducting interviews with several individuals during the 2020 U.S. presidential campaign, 15 liberal political activists in the American South (ages 19-75). The interviews contain a guided tour of users' recent social media posts with open-ended and retrospective questions that consider individuals' reasons for sharing political memes. These interviews are then analyzed via a coding scheme derived from the data. 


\section{Conclusions}

This study suggests that interpretive communities play a significant role in the circulation of political memes on social media through well-developed commonplaces. While much scholarship on memes emphasizes the spread of content online, this research suggests that political memes in particular also function through siloed online communities and serve as identity markers. This work contributes to continued research on political memes and their role in political identity development.

\section{References}

Jenkins, H., Ford, S., \& Green, J. (2013). Spreadable media: Creating value and meaning in a networked culture. NYU press.

Marwick, A. E. (2018). Why do people share fake news? A sociotechnical model of media effects. Georgetown Law Technology Review, 2(2), 474-512.

Milner, R. M. (2016). The world made meme: Public conversations and participatory media. MIT Press.

Ross, A. S., \& Rivers, D. J. (2017). Digital cultures of political participation: Internet memes and the discursive delegitimization of the 2016 US Presidential candidates. Discourse, Context \& Media, 16, 1-11.

Shifman, L. (2014). Memes in digital culture. MIT press.

Sparby, E. M. (2017). Digital social media and aggression: Memetic rhetoric in 4chan's collective identity. Computers and Composition, 45, 85-97.

Sparby. E.M. (Forthcoming). Meming the party divide: Representations of gender and identity in political memes. Enculturation: A Journal of Rhetoric, Writing, and Culture.

Tripodi, F. (2018). Searching for alternative facts. Media Manipulation Research Initiative. New York, NY: Data \& Society Research Institute. Retrieved from https://datasociety.net/research/media-manipulation. 


\title{
AClR
}

Selected Papers of \#AolR2020:

The $21^{\text {st }}$ Annual Conference of the

Association of Internet Researchers

Virtual Event / 27-31 October 2020

\section{PUTTING OUT THE DUMPSTER FIRE IN ONE "TRASHY" ONLINE COMMUNITY: AN ETHNOGRAPHIC STUDY}

\author{
Cindy Tekobbe \\ University of Alabama
}

\section{Background}

Online comments threads are fraught digital spaces, often approached with the commonplace advice to just not read them: "don't read the comments." Commonplace opinions argue that the comments add no value to the post/article/question; that they are a waste of time and emotional energy to navigate through the garbage to the potentially valuable content; and that they are a 'dumpster fire' of hate, inanity, racism, sexism, xenophobia, and so on. A great deal of research that surrounds online interactions demonstrates that comments sections reflect the greater culture wars where any kind of socially constructed transgression draws fire from "trolls" who are self-charged with enforcing the cultural norms (Nagle, 2017).

But what if online comments threads could be places of collaboration and community building, working against that notion of garbage fires? And how specifically could these spaces/places be constructed in support of a largely strife-free community?

Fanfiction, specifically slash fiction, is loved by its readers and writers, while being widely disparaged by greater culture as the domain of teen girls; texts with terrible grammar and spelling; and stories with juvenile plotting and characterizations, including the infamous Mary Sue who is little more than a writer inserting herself into her favorite fictional spaces (Ellis, 2014). In a conversation with my participants and fellow members of one slash fanfic Facebook group, many identified that they did not share with anyone their interest in reading and writing slash fanfic because it was described by others as the "trash" of the internet. Even as there is much scholarly writing that works against the notion that fanfic is merely trashy, the dominant narrative of socially awkward teenagers and their fan obsessions remains (Gray, et al., 2007). 
Working at the intersection of fan communities and digital rhetorics, with this project the author investigates how the community aspects of fandom - mutual support and investment of people whose relationships pivot on a shared affinity for a specific media - may translate into online moderation strategies that create collegiality in online groups, rendering comments as community-building acts rather than hostile spaces.

\section{Methods}

In this ethnographic study, the author spends three years belonging to and engaging with a slash fanfic Facebook group that through the creativity and active engagement of the moderators avoids many of the documented pitfalls of online commenting. Over this time period, the author acted as an observer, a participant, and a discussion leader, maintaining a co-presence as researcher and member (Pink, et al, 2016), working through the relationship and community practices of this group of more than 900 members who engaged in daily interactions without negative conflict in their comments. The researcher distinguishes negative conflict from conflicting ideas and opinions. Participants had different preferences and different opinions, difference in this group is considered a feature rather than a bug, but those differences are respected and valued rather than seen as transgressive behavior in need of overt oppression/suppression.

Specifically, with the study, the author asks, what is different about this Facebook group that it does not seem to reflect the hostility of discussions the researcher has observed in other Facebook group discussion threads? How much active moderation within this group is required to maintain collegiality and civility? What kinds of community engagement activities are enacted by moderators in the group to aid in member relationship building, both as they relate to the fandom and to the members' everyday lives? The researcher hopes that identifying how the moderators have structured and maintained their group can help inform a model of group moderation that minimizes the group conflict and takes the confrontational trash out of comments threads.

\section{Findings}

Through this study, the author finds that the slash fandom group relies both on the bonds of fan cultural relationships and careful and savvy online moderation strategies to build a productive space for members to interact without "drama" and discord. First, moderators build group identity by limiting the fandom-related discussions to a single slash "ship," while all other discussions can be on generally any topic. Second, moderators scaffold group relationships by implementing and supporting a weekly calendar of events which creates a space where group members can collaborate, cowrite, discuss, and share within a predictable framework. Third, group members actively construct relationships within this framework by sharing content and asking for and expressing mutual support, which adheres to the tone and practices of the group established by the interactivity of the moderators.

\section{References}


Ellis, E. (2014, Aug 7) In Defense of So-Called "Bad" Fanfiction: Shout out to Sirius/Remus. The Mary Sue. https://www.themarysue.com/in-defense-of-so-called-badfanfiction/

Gray, J., Sandvoss, C., Harrington, C. (2007). Fandom: identities and communities in a mediated world. New York University Press.

Nagle, A. (2017). Kill All Normies: Online Culture Wars From 4CHAN and Tumblr to Trump and the Alt-Right. Zero Books.

Pink, S., Horst, H., Postill, J., Hjorth, L., Lewis, T., Tacci, J. (2016). Digital Ethnography: Principles and Practice. Sage. 


\title{
ACR
}

Selected Papers of \#AolR2020:

The $21^{\text {st }}$ Annual Conference of the

Association of Internet Researchers

Virtual Event / 27-31 October 2020

\section{BATTERY LIFE (AND DEATH): STORIES FROM THE BLASTED LANDSCAPES OF A COPPER MINING TOWN}

\author{
Dustin Edwards \\ University of Central Florida, USA
}

Researchers have long paid attention to the damaging environmental effects of internet technologies. While early discussions often focused on how planned obsolescence from technology firms has led to a growing accumulation of digital waste (e.g., Gabrys, 2011), more recent work has examined not only the afterlifes of digital devices but also how devices are made of materials with multi-temporal contexts of extraction, production, and circulation (e.g., Cubitt, 2016; Hogan, 2016; Parikka, 2015; Roberts, 2016; Zylinska, 2017). Studying broader supply chains and deeper materialities of internet technologies_especially in an Internet of Things era-pushes the idea of "internet life" into new dimensions. What finite materials and rare earth sources (aluminum, gold, cobalt, copper, etc.) are used to power internet life? How are particular ecologies (mining sites, data center locations, petrochemical manufacturing sites, etc.) made vulnerable to power internet life? And how are qualities of life (in humans and multispecies life) put at risk to power internet life? This paper contributes to such questions by conceptualizing a thicker understanding of "battery life" - not only does battery life exist in the everyday sense of the term, but battery life entails a deeper, more mournful sense of environmental loss and devastation in particular landscapes.

\section{Methodology}

While distant perspectives of global supply chains and waste streams provide a certain view of such devastation, this paper engages methodological perspectives of story to offer an embodied and embedded view of internet life and death. As many scholars across fields of feminist science studies, environmental humanities, and Indigenous rhetorical studies have articulated, stories do not promise to offer a static, global view from nowhere; rather, in affirming the perspectival and the partial, stories pass off and relay knowledge in situated times and places to tell us something about the worlds we inhabit (e.g., King, Gubele, \& Anderson, 2015; Haraway, 2016; Tsing, Bubandt, Gan, \& Swanson, 2017). Drawing on published news reports, maps, corporate documents, and local and state government archives, as well as embodied knowledge rooted in site

Suggested Citation (APA): Edwards, D. (2020, October). Battery life (and death): Stories from the blasted landscapes of a copper mining town. Paper presented at AolR 2020: The $21^{\text {th }}$ Annual Conference of the Association of Internet Researchers. Virtual Event: AolR. Retrieved from http://spir.aoir.org. 
visits, memories, and place-based experiences, this paper tells a partial story of the Chino copper mine in New Mexico, USA.

\section{Stories from a Copper MIne}

One of the largest copper mines in the United States, the Chino mine is currently owned by Freeport McMoRan, the second largest producer of copper in the world and the largest publicly traded mining company on the planet. The massive, open-pit of the mine has grown so big that it swallowed the entire town of Santa Rita, New Mexico. Schools, hotels, homes, and a hospital were moved or demolished to make room for the expanding perimeter of the pit. But the expanding mine pit has done more than bulldoze a town and displace a community. Years of poorly regulated mining operations have polluted groundwater and airways. Though environmental oversight of the mining industry has tightened (and loosened back again) over the years, hazardous materials have been found in groundwater and plant life near the mine due to several reported spills, leaks, and ruptures. And then there are the occupational hazards and chronic health problems experienced by those laborers on the front lines-those who have consumed copper dust and handled toxic materials or those whose bodies have been crushed by heavy machinery, among other occupational dangers. As a major source of economic development and generational prosperity in an otherwise sluggish economy, the story of the mine is a complex tale of land demolition and restoration; of toxic spills and tightened environmental regulation; and of precarious labor conditions and economic development.

\section{Why Tell Such Stories?}

Telling embedded stories of places such as the Chino Mine is important for internet studies research, because such stories offer visceral reminders of how life is unevenly experienced in the service of powering the lively machines that comprise the internet and its connected platforms and devices. Consider, for example, how a single iPhone contains about 15 grams of copper. And, of course, that number intensifies at scale: 1 million iPhones contain about 15 tons of copper. There are bits of copper traveling in the pockets of people all around the world, with each gram of precious metal carrying its own unique story of how it was extracted from land and reprocessed to its current state. In our pockets and bags, then, are stories of toxic tailings, of lands blown to smithereens, and of laborers living and dying on the job. These damages, whether consciously registered or not, are always tethered to the stories researchers tell (and don't tell) about digital devices and platforms.

As internet researchers continue to investigate the confluence of digital platforms and material infrastructures, telling and listening to place-based stories of environmental harm provides thicker understandings of internet life (and death). In doing so, researchers might advocate for better sustainability practices in industries connected to what Van Dijk, Poell, and De Waal (2018) have called the platform society. As Van Dooren and Rose (2016) argued, "Telling stories has consequences, one of which is that we will inevitably be drawn into new connections and, with them, new accountabilities and obligations" (p. 89). The tale from the mine is just one story among many that internet researchers can investigate to elicit new accountabilities to make worlds more livable for a range of human and nonhuman life. 


\section{References}

Cubitt, S. (2016). Finite media: Environmental implications of digital technologies. Duke University Press.

Gabrys, J. (2011). Digital rubbish: A natural history of electronics. University of Michigan Press.

Haraway, D. (2016). Staying with the trouble: Making kin in the Chthulucene. Duke University Press.

Hogan, M. (2015). Facebook data storage centers as the archive's underbelly. Television \& New Media, 16(1), 3-18.

King, L., Gubele, R., \& Anderson, J. R. (2015). Survivance, sovereignty, and story: Teaching American Indian rhetorics. University Press of Colorado.

Parikka, J. (2015). A geology of media. University of Minnesota Press.

Roberts, S. T. (2016). Digital refuse: Canadian garbage, commercial content moderation and the global circulation of social media's waste. Wi: journal of mobile media, 10(1). Accessed February 29, 2020 from http://wi.mobilities.ca/digitalrefuse/

Tsing, A. L., Bubandt, N., Gan, E., \& Swanson, H. A. (Eds.). (2017). Arts of living on a damaged planet: Ghosts and monsters of the Anthropocene. University of Minnesota Press.

Van Dijck, J., Poell, T., \& De Waal, M. (2018). The platform society: Public values in a connective world. Oxford University Press.

Van Dooren, T., \& Rose, D. B. (2016). Lively ethography: Storying animist worlds. Environmental Humanities, 8(1), 77-84.

Zylinska, J. (2017). Nonhuman photography. MIT Press. 